\title{
From Locations to Dislocations: Frank Nabarro Turns Obstructions into Opportunities
}

With quiet humor and a strong will, Professor Frank Reginald Nunes Nabarro has endured university politics and a country's battle with apartheid to become an unquestionable scientific force in his adopted country and worldwide. He brought Nabarro-Herring creep to materials science, and through his book on dislocation theory, showed himself to be one of the mathematical wizards of that field. He continued to go deeper into the field throughout his schooling and early career in the United Kingdom and his 50-plus years in South Africa at the University of the Witwatersrand, Johannesburg. Always questioning and probing, he is clear about what he knows and what seems beyond his or anyone's grasp.

When he heard that a young student in his department was eager to meet him, but felt unworthy to be with someone so celebrated, Frank promptly introduced himself and genuinely wondered how they had not made each other's acquaintance earlier. He wanted to understand her scientific work, aware that there is always something more to learn.

Frank Nabarro came to his first Materials Research Society meeting at age 87, attending the 2003 MRS Fall Meeting in Boston. When asked why, he apologetically admitted that an invitation to an event happening in parallel to the meeting tipped the balance, with his real goal being to meet with long-time friends and colleagues. Yet, as he has done so often in his life, he leveraged a chance circumstance into something more. I was unabashedly excited to be introduced to him by John Cahn, who knew my metallurgy roots and the dislocation interests of my own father Robert L. Fleischer. However, the conversation quickly moved beyond my admiration, and the next thing I knew, I was making plans to go to South Africa the following week both to attend the AfricaMRS meeting and to interview Frank Nabarro. I landed not only in South Africa, but as a guest in Frank Nabarro's Johannesburg home.

Starting each day with a breakfast of toast and jam, a walk to the bus, and fish or meat with vegetables each night, I quickly settled into Frank's routine. Sitting in his dining room after dinner, surrounded by his books and by musical instruments his wife Margaret had cherished, we began our interview.

When did you first find interest in science?

Let me tell you the truth. I was born in London along with my sister. My father was a tax inspector, and we moved every few years. When we moved to Cleethorpes, a little town at the mouth of the river Humber, I went to school there. They had a small woodwork shop, and a small chemistry lab, each of which took half the

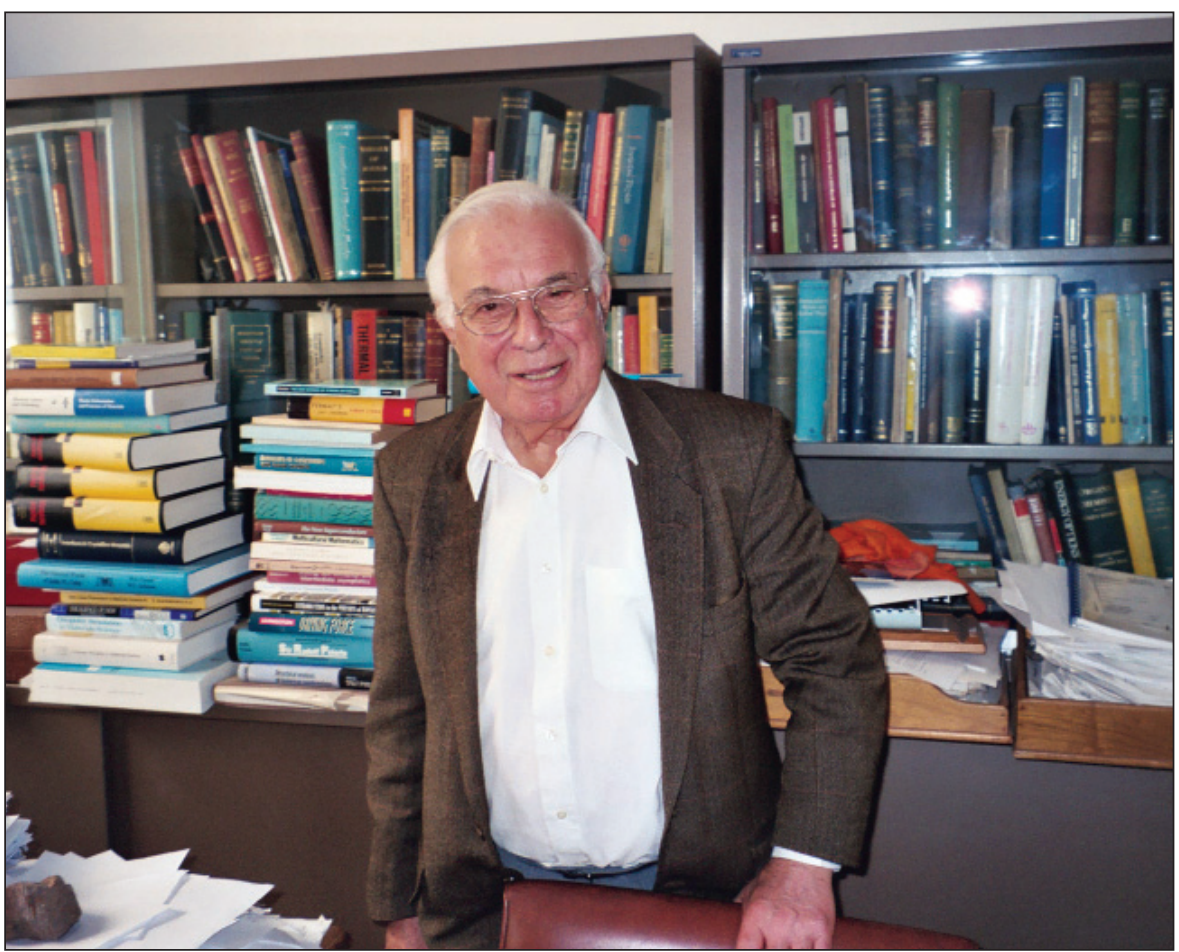

class. So you changed halfway through. If you were the worst at woodwork, you had to look after the glue pot. This is where I found myself and I thought, "This is no game at all," so I said, "Can I please do double chemistry?"

The year before my school-leaving certificate, my father was moved to another town. My new school could not accommodate the combination of subjects I was taking, and I needed to find one more course. They said, "You have been doing well in chemistry-why don't you try physics?" I duly got an A or " 1 " in physics. I thought, "Well, you know, this is easy." That got me into physics.

I had aimed to go to Trinity College, Cambridge, but while I had been taught physics, I had not been taught examination techniques. I still remember it. You had to prove the Poiseuille formula for the flow of liquid through a round tube. I couldn't remember the trick for doing that proof. Instead of getting on with the next question, I spent half an hour failing to solve that one. So, I didn't get into

Profiles \& Perspectives explores the people behind the profession of materials research.
Trinity College; I got into New College, Oxford, which is a gorgeous college. Although it has some modern buildings, it has its nearly original medieval courtyard, a bit of the old city wall of Oxford, and the original chapel and hall and cloisters. It is probably the best show college in Oxford, although Christ Church is more grand, and Magdalen is later and more ornate.

The way you did a physics degree was by doing one year of mathematics and two years of physics, by which time the man who taught us to blow glass had decided that I was not going to be good at blowing glass. Let me explain. This is one of the oldest applications of materials science and engineering. In my young days, scientific apparatus was made of glass joined by sealing wax. Due to my glass-blowing ability, I decided I had better be a theoretical physicist, which meant doing another year of mathematics. I duly got my degree, then went to Bristol for my first research degree. The first degree in Oxford is called the Bachelor of Arts. The first research degree was called Bachelor of Science. I think the only living people to still hold a Bachelor of Science degree are Lady Thatcher and me! England has the system in which you have external examiners for degrees, and 


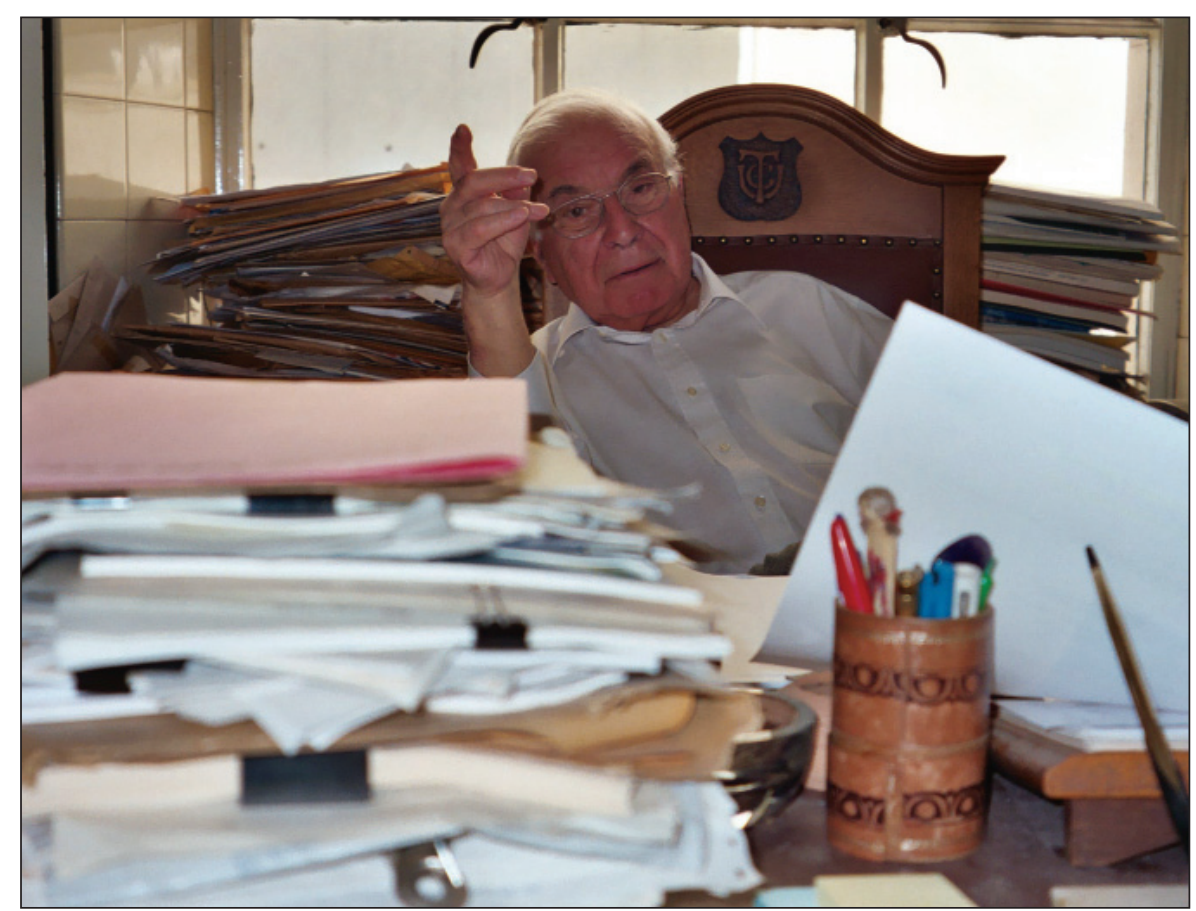

my external examiner for physics was Nevill F. Mott at Bristol. We wrote our first paper together-which was completely wrong-in an attempt to understand solution hardening. We assumed the dislocation was rigid. If the dissolved atoms clustered into little spheres, the flow stress remained exactly the same. As you know, there is a thing called "age hardening." We published a little note on that just before the war [World War II], which-I say-was completely wrong. I published a couple of other papers, including the first on the influence of stresses on the shape of a precipitating particle. I did not know the difference between a coherent and an incoherent precipitate. It turns out this work related to an incoherent one. But the result is much the same as for a coherent one. The precipitate wants to be either flat or a needle. I made a very hand-waving account, showing essentially the competition between elastic energy and the kinetic diffusion. Very hand-waving, but terribly original.

Then the war came. I worked in the Army Operational Research Group. The story of Operational Research is that it was invented by the Royal Air Force, and their individual arms-bomber command, fighter command, and so on-had their own individual research sections. The army decided it would start one on antiaircraft. I worked for a rather short time on the air defense of London-under Blackett-Patrick M.S. Blackett, 1948 Nobel Laureate in physics. Other members of the team included Andrew
Huxley, who was a year older than I and became a Nobel Laureate. It was quite a good team. The first man who ran it was J.A. Ratcliffe, who was an expert on the ionosphere. I also worked with Basil Schonland, a South African. This is the time when I met Margaret. At the end of the war, I got a medal-the MBE [Member of the Order of the British Empire], which is, I think, about the lowest civilian order you can get. But it is an order.

\section{"In those days, you did not apply for jobs. The big people just arranged for you to go."}

Mott and I came together again after the war. One of the first things we realized was that a dislocation is flexible. I worked out very crudely the flexibility, and once you had that, you got the situation where if the particles were very small, the separation between them was small, and the stress could not bend the dislocation into curves sharp enough for it to sink into the potential troughs. You could calculate the critical size where the radius in which the stress field of the particle could bend the dislocation was the same order as the separation between particles, and that explained the peak of age-hardening. After that, to consider an equilibrium precipitate, you have to get surface energy. Surface energy goes as the square and elastic energy goes as the cube of the particle radius, so for a large particle, the surface energy becomes unimportant, and it breaks away from being coherent. You then get over-aging. We worked all that out. Then a man called Robert L. Fleischer pointed out that you had to consider not only the stress field of the inclusion, but also the fact that the precipitate had a different elastic modulus, and therefore it would influence the stress field of the dislocation.

Then there is the formula of EshelbyFrank-Nabarro for a pile-up of dislocations. It is all to be found, by the way, in an issue of the Proceedings of the Royal Society A, Number 1744, called "The Beginnings of Solid State Physics" [Nevill Mott, ed., Vol. 371, 1980, pp. 1-177]. The equations for the pile-up say that the sum of one over the distance from the dislocation you are considering to all of the other dislocations is proportional to the applied stress. That is a totally insolvable equation, you would think. I went to a professor of mathematics, H. Heilbronn, who said, "Oh, that is quite trivial," as he related the formula to one about where certain polynomials have the value zero, and calculated it all in his head. I said, "Would you like to write a joint paper on this?" He said, "For heaven's sake, no. It would ruin my reputation. First of all, the mathematics is trivial. Secondly, it has an application."

John D. Eshelby and F. Charles Frank, who were both terribly clever, extended it from the simple case for a single-ended pile-up source of length $L$ to such things as a double-ended one with the source in the middle and a parabolic distribution of dislocations. They published this famous paper of Eshelby, Frank, and Nabarro [Phil. Mag. 42 (1951) p. 351].

What was it like working with Frank and Eshelby?

Charles was terrific. Eshelby was sort of odd. Total bachelor. Died young because he had rheumatic fever. He had an extraordinarily weird sense of humor. But terribly, terribly clever. He would just write down solutions to things that we could not touch.

\section{How did you end up at Birmingham University?}

Mott said, "You are going to Birmingham to work with Cottrell." In those days, you did not apply for jobs. The big people just arranged for you to go. So I went to Birmingham to work with [Allan] Cottrell. Meanwhile, Margaret, after declining several times, decided she would marry me. We went to Birmingham. We had two children there. I continued writing the book, which finally came out in 1967 with 


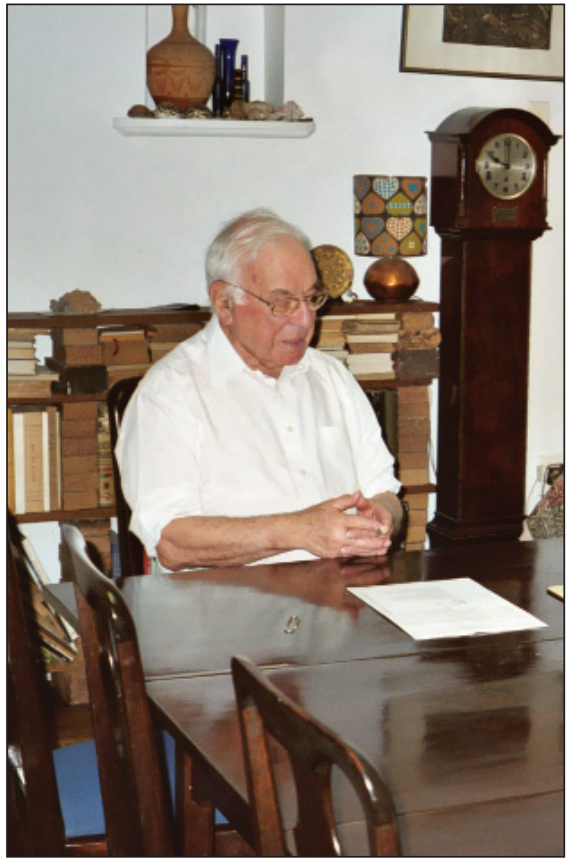

the title Theory of Crystal Dislocations, that I had started in Bristol. I was at Birmingham for four years, and I did all sorts of papers, had my first PhD students, and so on. I did not finish the book [there]. I received invitations, including one to go to Simon Fraser University, which was then quite new. Our oldest son was asthmatic, so the idea of going to the damp Vancouver did not seem like a good one. We came to Johannesburg with the understanding that we would stay for five to ten years.

The man who recruited me was Schonland, the same South African Margaret and I had met during the war. Unfortunately, he left here to take up the directorship at Harwell about 18 months after we arrived. I was left to look after myself, which was very unpleasant in some ways because the vice chancellor was a very unimaginative civil engineer, and he thought I was an awful pain in the neck. During one of our disputes, I said I thought I might leave. He wrote me a letter, which is in the university archives, saying he hoped my resignation would not be long delayed. Well, of course, if somebody writes you a letter like that, you just have to dig in and outlast him. I went on in research, and I became a fellow of the Royal Society, at which time, I must say, the vice chancellor, who was an honest man, apologized. There were only two fellows in South Africa of the Royal Society. Schonland and R.W. James at Cape Town.
Before that, there was the time when all new faculty were on three years' probation. The day the university council was to meet, to consider my probation, I was called by the vice chancellor and told they had a petition of all the members of physics that I should not be confirmed. I said, "Can I see?" and he said, "Yes." I said, "Well, where is the name of Doris Wilsdorf?" He said, "They thought you knew her too well-or she knew you too well." "And where is the name of Mr. Kushlick?" Mr. Kushlick and I were Jewish, so they said, "Well, you know, they thought he was rather biased." I said, "So, it was not all the members." He said, "Well, not quite."

After a year, they said it was all a big mistake. Some of them, of course, had been hoping for the job. Essentially, they were living in British colonial time and I had been brought here to wake the place up. The department had really been a service department, teaching the elements of physics to engineers, medical students, dentists, and architects. The first thing I did was change the labels on the department files from "Engineering, Science" to "Science, Engineering." We did quite well, and I think there is no doubt that we are now the leading department in the country. The only thing that upsets me is that the department has been doing better since I retired.

\section{“Experimental observation and theory tend to not agree, in which case, we have to ask what to do with the theory."}

I became dean in time, and deputy vice chancellor in time. By and large, you expected to be re-appointed as deputy vice chancellor, but I was not. It turned out to be a mercy. I returned from a year's sabbatical, but not as head of department because, they said, it would have been unfair to the man who had been acting head when I was deputy vice chancellor to have been pushed down. So I went back into research, and the result is I am still sort of gainfully employed, whereas if I had done another three years in administration, I would have been on the shelf. When I retired, CSIR took me on as a consultant.

\section{As a theorist, how much have you worked} with experimentalists?

Never as closely as I wanted. Frequently, I was concerned with the interpretation of experimental results. Just under half of my work has been strongly influenced by experiment. Experimental observation and theory tend to not agree, in which case, we have to ask what to do with the theory.

When you read the literature and see discrepancies, do they plague you?

There are lots of things I cannot understand-yes. But discrepancies? I recognize, for example, that it may have been silly to work out the case where you have small isolated dislocation segments going through a potential field where you have a lot of equally spaced localized obstacles; that theory is quite complicated. I worked it out, but it is utterly unrealistic. Fred Kocks [U.F. Kocks] has worked out the situation where you have, similarly, identical obstacles, but scattered at random over a glide plane, and a single dislocation moves over them. He says, reasonably and characteristically, that his model is much more realistic than mine, which is true, but his model is not a theory because in at least one place he refers to computer models. Moreover, the computer models apply to point obstacles, and we know they are not point obstacles, which makes the theory very different. The two-dimensional problem is verging on the impossible. There is also a wonderful recent paper by Michael Zaiser, who worked it all out with "extreme limit statistics." It is full of theorems. It ends up by showing that the strain increases like $t^{\beta}$, where $\beta$ is the ratio of $k T$ to the energy required to get it over an obstacle without thermal activation and $t$ is the time since you first applied the load. Now everybody knows that is about 30 . So the theory shows $t^{1 / 30}$, the experiment shows $t^{1 / 3}$. So apparently if you do the mathematics right, you get the answer wrong. The subject is just a mess, and it is too difficult for anybody, still. To consider a single dislocation moving, one knows that the only semi-plausible theories of $t^{1 / 3}$ involve the interactions between many dislocations. That is, when a dislocation overcomes one obstacle, then it surges forward, puts stress onto the neighbors, and another one which was stuck will then go over. There are three theories, all of them the most hideous approximations, in ridiculously primitive models, but they all depend on that. The chance of really getting to $t^{1 / 3}$ seems minute. If you do it with powerful mathematics, you get $t^{1 / 30}$.

I've heard you described as "an island in a scientific desert in South Africa."

That was not quite true, to the extent that R.W. James of Cape Town, for example, had a master's class which had two future Nobel Laureates. But Cape Town is a long way away. And that was the 
only distinguished physics department. Here, we had the famous work of paleoanthropology of Phillip V. Tobias, following on Ramond Dart, and so on. So there were some high points.

How did the national politics over the years affect your work here?

Actually, not much. I mean, we and Cape Town were very angry that many universities just said they would boycott the South African universities, failing to recognize that we and Cape Town strongly-and the other English-speaking universities, Natal and Rhodes-were both opposing the government. Actually, the government was not all that unreasonable in its treatment of us, but certainly we did suffer a bit, and sometimes we had nasty events. We got no praise for standing up for academic freedom. On the other hand, I have never had trouble traveling. A South African colleague of mine went to Harwell to do some work, and some people said, "No, no, you come from South Africa," but a lot of people have joint appointments at Harwell and Oxford, so he went to work at Oxford. I visited Sandia National Laboratories in Albuquerque. I stayed with Bert Westwood [Albert R.C. Westwood], who was actually the boss of the organization, but his security man said I came from South Africa-but I was not a South African citizen-and would not let me in. It turned out that several months earlier, the ban had been lifted, but he had not actually read his mail!

That was the only time, I think, that I was really worried about it. But South Africans did have a bit more worry. Basically, I think, in physics, this was not severe. It was severe in the social sciences.

What about during apartheid? Did you feel limited as far as the pool of scientists you had to draw on?

Obviously, one worried what was going to happen. I mean, the whole thing could so easily have turned into serious violence. But, by and large, you see, the tensions did tend to be confined to the wild young men who burned flags and so on. Our students were wild occasionally. The leader of them was a student of mine, Mark Orkin, who later received a Rhodes Scholarship and went to Oxford, obtained a PPE degree, which is called Politics, Philosophy, and Economics, and he now heads the Human Sciences Research Council here. He started as a physicist. His father had been very high up in AEG, then one of the biggest German engineering firms. In his old age, he wanted something to do, and Mark

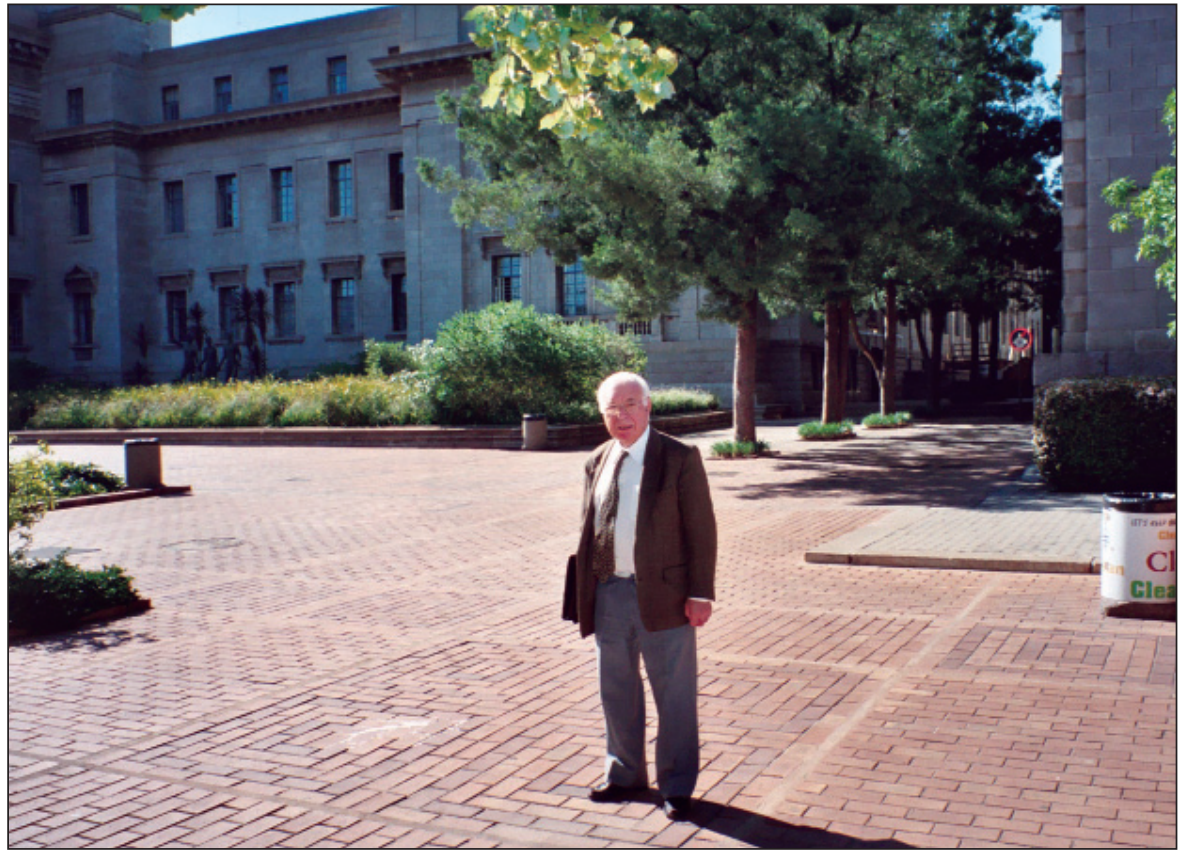

arranged for him, who was 80 or so, to become my part-time research assistant.

As I told you, we started to breed in captivity and had three more children. We built on those three bedrooms and a bathroom. John Cahn came out and stayed. That was after Margaret died. All kinds of people stayed. It is amazing sometimes; I will meet somebody, and they will say, "Oh, yes, I so much remember that party in your house," and I have completely forgotten. Margaret and I had many parties. You tend to live fairly simply with five children in private schools. Usually we introduced visitors to the local people from the University of Pretoria and CSIR.

\section{"Assuming political stability remains, I think African science is going to improve."}

What do you see in the future of African science?

Assuming political stability remains, I think African science is going to improve. People at this type of technical meeting tend to moan about their government. I do not know if you noticed, but people at the MRS-Africa Meeting all say nice things about the South African government. There are interactions between countries in Africa. We have a laser center that joins scientists in different parts of Africa, encouraging the use of lasers throughout the continent. This whole MRS-Africa business is a very determined effort to create that sort of collaboration.
Many scientists frequently shift to different fields. It seems like you have kept fairly near to your roots.

Yes, I shifted very little. During a total eclipse of the sun, there was one paper on the way in which a sudden shutdown in solar radiation interfered with radio propagation, but that was sort of "wished" on us as an opportunity to get students out on field work in physics. There were a few biological ones: on dislocations, disclinations, and related concepts in biological systems. There was one on the interpretation of some funny interference fringes.

The lack in "shifting" is partly due, of course, to this natural isolation. If you have to be self-reliant, you have to try to know everything in that field; it does not give you much time to know anything in any other field.

\section{How did you get involved in dislocations?}

How I got into dislocation theory-that is another of these accidents. Mott set me to work on magnetic hardness, Bloch walls, and point obstacles. I worked on it as far as I could, but Mott did not seem to be happy with what I did, so he sent it to G.I. Taylor-whom he enormously admired-and Taylor responded that it did not make any sense to him. Taylor was a pioneer in showing how lattice defects produced mechanical hardness. Then I discovered a German group who had done it all already-and better-so Mott said, "Well, look, you have been looking at what happens when two-dimensional objects are held up by obstacles. There are things 
called 'dislocations,' which are onedimensional objects held up by obstacles. Why don't you look at them?"

As you say, I stayed there essentially. I had started writing a book, which certainly makes one concentrate, while I was still in Bristol. Then I had to finish the book. I realized that in order to get anywhere, I had better stick to areas where I had a strong background.

\section{What more do you hope to do?}

There is a paper by a group which is determined to prove that diffusional creep does not exist, which, in an extraordinarily detailed analysis, deals not with metals, but with $\mathrm{Al}_{2} \mathrm{O}_{3}$. They state that there is solute drag on a gliding dislocation, but there is no solute drag on a climbing dislocation. It seems to me that there has to be, because when the dislocation climbs, it has an atmosphere with a high concentration of so many atoms on one side and a low concentration on the other. They move through the lattice. There must be drag. John Cahn persuaded me that it was more complicated than I had thought. Whether I will be able to do that problem, I do not know, because the glide problem turns out to be mathematically monstrous. John says the problem is harder essentially because in glide you start with a solute cloud which is symmetrical about a dislocation. Then you perturb it. In climb, you start with one which is not symmetrical in the direction in which you are moving. So it is an even worse problem. That is one I would like to do.

Any message you would like to pass on to future generations?

The message of Mott: Try to get a picture of what is going on, and then make the simplest possible theory of it that contains the essential facts. When it gets complicated, leave the details to somebody else. All of which was said by Alvin Weinberg-much more clearly-long ago.
Weinberg, who wrote Reflections on Big Science [MIT Press, Cambridge, Mass., 1967], said that when the subject is in its creative stage, the style is classical. When it becomes baroque, the danger signals are up. I think that is another way of putting the same message, that if you have got the basic picture-unless you are actually involved in engineering and design-filling in all the details is not terribly helpful.

While looking for elegant answers, Frank Nabarro does not shy away from complexity. Rather, he takes on the challenges before him to seek the simple truths that Mott espoused. And while Frank Nabarro attributes chance and circumstance to many of his career choices that led him to study dislocation theory in South Africa for over 50 years, one wonders if perhaps it is his inner will and core gifts that orchestrated him to land just where he needed to be.

The interviewer was MRS Bulletin editor Betsy Fleischer.

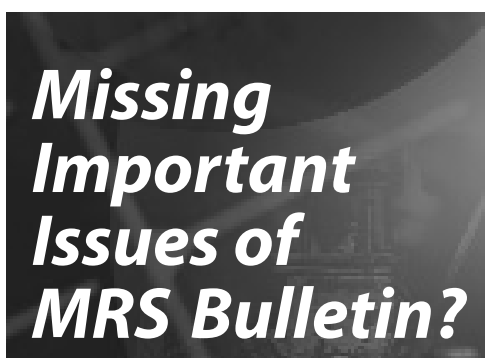

Back Issues are

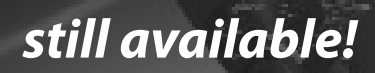

Contact MRS for details -

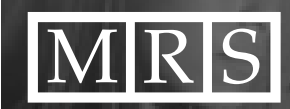

506 Keystone Drive

Warrendale, PA 15086-7573 U.S.A.

Tel: $724-779-3003$

Fax: 724-779-8313

E-mail: info@mrs.org

www.mrs.org/publications/

\section{MRS Bulletin Back Issues}

Order by Volume and Issue Number. \$30.00 per issue.

\section{VOLUME $28 \cdot 2003$}

No. 1 Microelectronics Packaging and Integration

No. 2 Single-Event Upsets in Microelectronics

No. 3 Superhard Coating Materials

No. 4 Cellular Solids

No. 5 Photonic Materials for Optical Communications

No. 6 Materials Science of Adhesives-How to Bond Things Together

No. 7 Hydrogen Effects, Nanoscale Science, Organic-Based Magnets, Ancient Glass, Film Archiving, and Superbikes

No. 8 Advanced Fabrics

No. 9 Ultrahigh-Temperature Materials for Jet Engines

No. 10 New Materials for Spintronics

No. 11 Inkjet Printing of Functional Materials

No. 12 New Frontiers in the Application of Neutron Scattering to Materials Science

\section{VOLUME $27 \cdot 2002$}

No. 1 Mechanical Properties in Small Dimensions

No. 2 Science and Technology of Shape-Memory AlloysNew Developments

No. 3 Alternative Gate Dielectrics for Microelectronics

No. 4 Combinatorial Materials Science

No. 5 Optical-Fiber Sensors

No. 6 Electroactive Organic Materials

No. 7 Vertical-Cavity Surface-Emitting Lasers

No. 8 Portable Power: Advanced Rechargeable Lithium Batteries

No. 9 Hydrogen Storage

No. 10 Advances in Chemical-Mechanical Planarization

No. 11 Advanced Flat-Panel Displays and Materials

No. 12 Silicon, Surface Dynamics, Friction, Proteins and Synthetic Nanosystems, and Ancient and Modern Steels 